Original Article

\title{
Parental entries on hearing in Child Health and Development record: How reliable in early detection of paediatric hearing loss?
}

\author{
De Alwis A S R ${ }^{1}$, Y Yasawardena A D K S N ${ }^{2}$, Rubasinghe $\mathrm{M} \mathrm{S}^{2}$, Wariyapola A D 3 \\ ${ }^{1}$-Senior Registrar in ENT, National Hospital of Sri Lanka \\ 2 -Consultant ENT and Head \& Neck Surgeon, Lady Ridgeway hospital for children, Sri Lanka \\ ${ }^{3}$-Medical Officer, Lady Ridgeway hospital for children, Sri Lanka
}

\begin{abstract}
Aim

To assess the effectiveness of parental entries regarding functional hearing in the Child Health and Development Record(CHDR), in patients with severe to profound hearing loss, and detection of the hearing issues by the public health midwife(PHM)

\section{Material and Method}

A descriptive cross sectional study was carried out among parents/caregivers of children with severe to profound hearing loss who underwent cochlear implantation before the age of 5 years from 01.01.2017 to 31.12. 2018 at Lady Ridgeway hospital for children, Sri Lanka. An interviewer administered questionnaire was used based on the hearing assessment in CHDR

\section{Results}

The age of the mother at the birth of the index child spans from 17years to 50 years. Majority ( $64.1 \%$ ) had another child older to the index child. The majority were diagnosed between 18-24 months. The age of cochlear implantation spans from 9 months upto 5 years. Average waiting period was 2 years. The correct entries were observed as follows: $20.8 \%$ at birth, $22.7 \%$ at 1 month and $22.6 \%$ at 4 months, 7 months, 9 months and 12 months respectively. Among those who have not marked or marked incorrectly, 45.9\% stated that they couldn't recognise the hearing impairment and $23.4 \%$ stated they were reluctant to accept it. Only $4 \%$ of these children were referred for further assessment by the PHM

\section{Conclusion}

Parental and the PHM's assessment of a child's hearing is not a reliable indicator to detect early sensorineural deafness
\end{abstract}

Keywords - CHDR, hearing loss, children

Copyright: (C) 2021 De Alwis ASR et al.

This is an open access article distributed under the Creative Commons Attribution License (CC BY 4.0) (C) (1) This license lets others distribute, remix, tweak, and build upon the work, even commercially, as long as they credit the original author for the creation.

Funding: None

Competing interest: None

Correspondence: Dr. ASR De Alwis (2shashini@gmail.com) 


\section{Introduction}

Deafness is considered as one of the most common neglected disabilities and which is worse in developing countries ${ }^{1}$. According to the World Health Organization (WHO), 34 million children suffer from hearing loss. Children whose hearing loss is not corrected before the age of brain development may suffer from permanent impairment of speech and language ${ }^{2}$, which highlights the importance of detection of hearing impairment by parents or caregivers at a very early stage. In Sri Lanka provision of hearing aids and cochlear implantation are carried out in several government hospitals free of charge to provide the highest possible care to the patients. Hence early detection of early onset of hearing loss is of paramount importance.

The Child Health and Development Record (CHDR), which is developed and issued by the Family Health Bureau of the Ministry of Sri Lanka, is the main document in the National Growth Monitoring and Promotion programme for children under 5 years. It is a comprehensive health record which documents an individual child's health history which includes their growth, immunization, developmental milestones and nutrition from birth till 14 years of age. It is supposed to act as an important tool in identifying auditory issues by health care workers and parents. This is issued free of charge to all newborns and a significant portion of the country's health budget is allocated for this record.

The outcome of this effort relies on the effectiveness of correct and timely entries by the parents to detect children who need frequent monitoring or special referrals. Monitoring the hearing response and relevant entries are located on page 11 of CHDR, which needs to be filled by the parents at specific time intervals. It is expected to recognize or identify hearing issues by both parents and caregivers where appropriate intervention can be initiated.

\section{Method}

A descriptive cross sectional study was carried out among parents/caregivers of children with severe to profound hearing loss who underwent cochlear implantation before the age of 5 years from 01.01.2017 to 31.12. 2018 (2 year time period) at Lady Ridgeway hospital (LRH)for children, Sri Lanka.

Parents/caregivers of children who underwent cochlear transplantation before the age of 5 years who are carrying a new CHDR (issued after 2004) were included in the study while those who refused to participate were excluded. Parents/ caregivers, who met the above criteria were interviewed and the examination of CHDR is carried out as they attend the Paediatric ENT clinic for regular follow up.

An interviewer administered questionnaire was used to collect data. The structured questionnaire, which consists of 17 questions, was locally designed and based on expert's comments, entries by parent/caregiver and the Public Health midwife in CHDR, which is located on page 11 and page 13 respectively.

Ethical clearance was obtained from the ethical review committee of LRH, Colombo. Informed verbal consent was obtained from mothers before interviewing them. Refusal to participate was respected. 


\section{Results}

Parents/caregivers of $53(74.6 \%)$ children replied to the questionnaire.

The age of the mother at the birth of the index child spans from 17 years to 50 years. The ethnicity consists of $82.7 \%$ being Sinhalese, $9.6 \%$ being Muslims and $5.8 \%$ being Tamils.

We observed that $64.1 \%$ had another child elder to the index child and $38.2 \%$ more than one child elder to the index child. (Graph 1).

\section{Number of children elder to the index child}

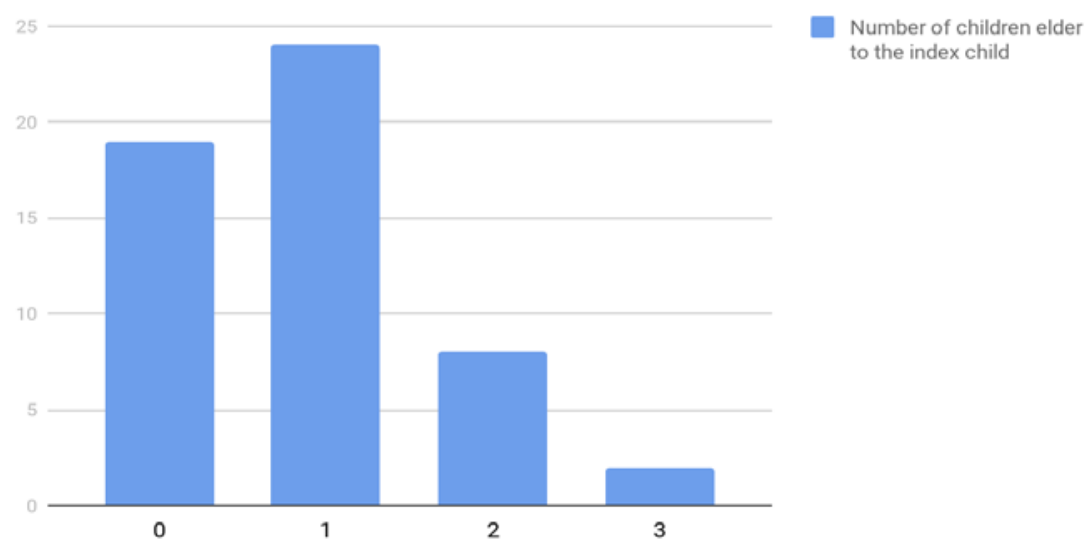

\section{Graph 1: Number of children elder to the index child}

$39.6 \%$ of the mothers are housewives while the rest are employed. From those who are employed, the majority are unskilled workers (52.4\%), while $28.6 \%$ are skilled workers and $19 \%$ are professionals.

Majority of the mothers were educated upto GCE O/L (52.8\%) Only 47.2\% had educationupto GCE A/L or higher education(Graph 2).

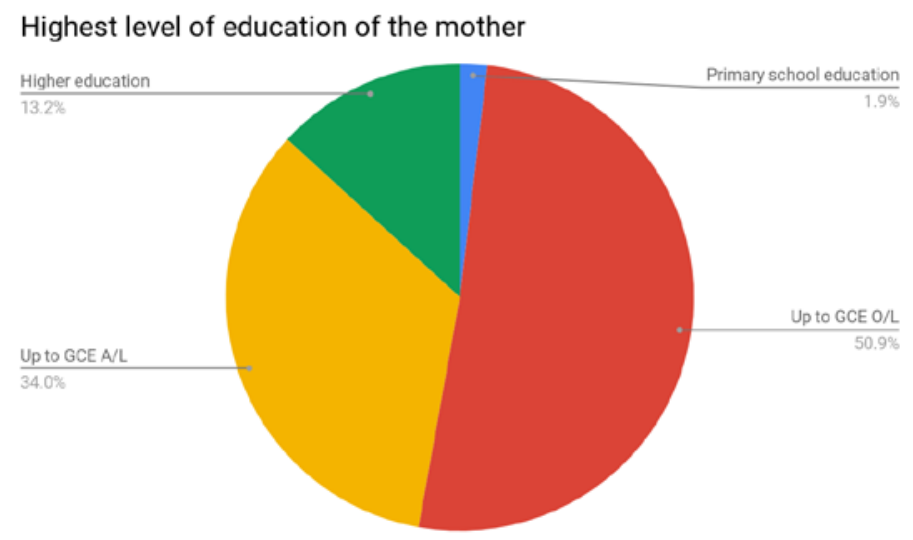

Graph 2: Highest level of education of the mother

The age of the child at the first diagnosis of the hearing loss spans from less than one month upto 2 years and 8 months of age. Most of the children were diagnosed between 18 - 24 months (Graph 3). 


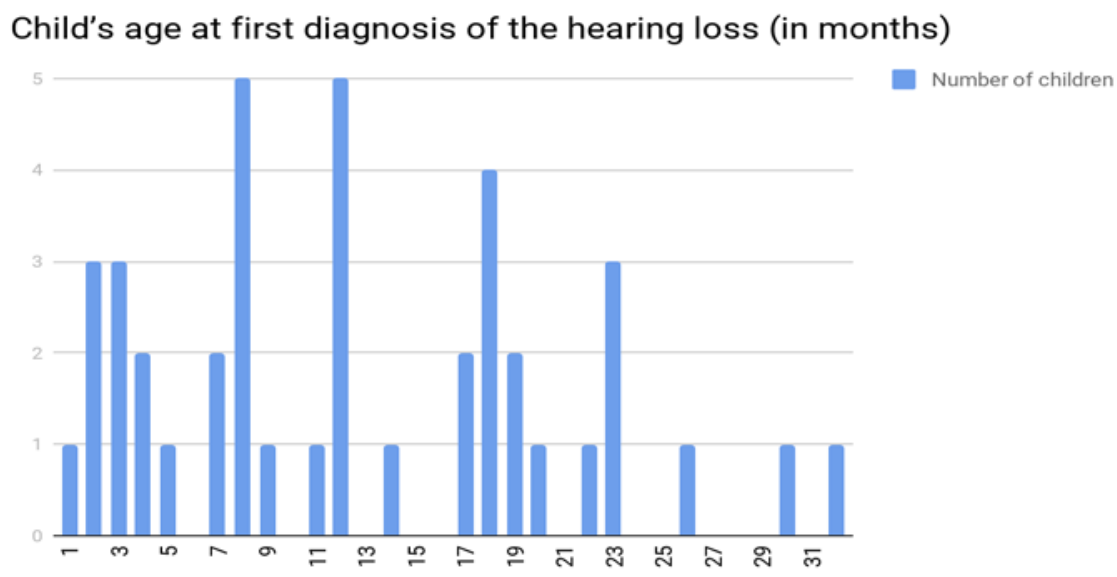

Graph 3: Child's age at first diagnosis of the hearing loss (in months)

The age of cochlear implantation spans from 9/12 upto 5 years of age. The majority had their implantation between 3-4 years. The waiting period for the cochlear implants span from 5 months to 4 years, and the average waiting period was 2 years .

Accuracy of entries on functional hearing in the CHDR at various milestones are as follows.

At birth only $20.8 \%$ have marked correctly at newborn, while $45.3 \%$ have marked incorrectly and $34 \%$ have not marked at all. At 1 month, 4 months, 7 months, 9 months and 12 months, $22.6 \%$ have marked correctly, $22.6 \%$ and $54.7 \%$ haven't marked at all (Graph 4).

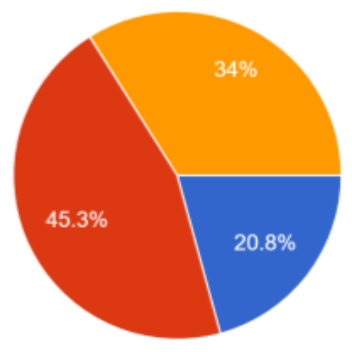

At Newborn

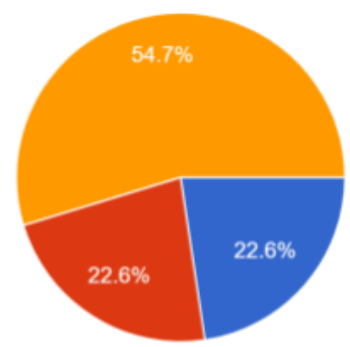

At 7 months

\section{Parental entries on functional hearing in each milestone}

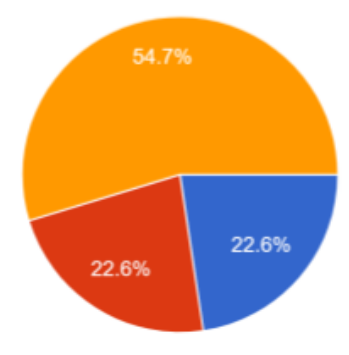

At 1 month

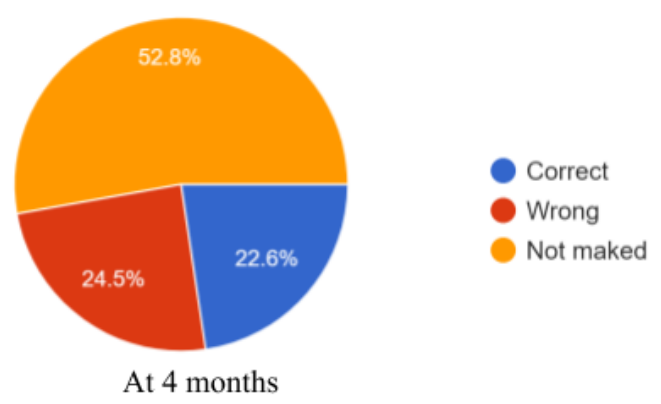

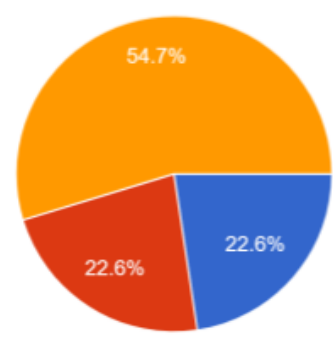

At 9 months

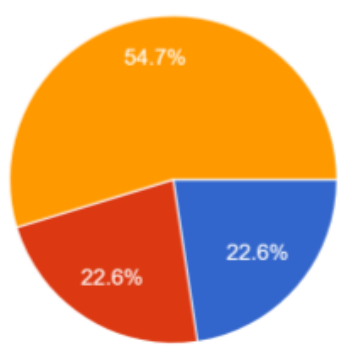

At 12 months

Graph 4: Parental entries on functional hearing in each milestone 
The majority (45.9\%) of parents who have not marked or incorrectly marked stated that they couldn't recognize the child's hearing impairment. $24.3 \%$ of parents stated that even though they suspected a hearing loss, they were reluctant to accept it. Some parents $(1 \%)$ did not consider it a necessity to mark the CHDR. Few stated that they marked as normal hearing since they were reassured by PHM that the child is having a speech delay rather than a hearing impairment.

There was a child whose parents are deaf and thus, could not assess the hearing. And few parents stated that due to family issues they couldn't concentrate on their child's hearing.

Taking account of PHM's responses regarding incorrect or no entries, we observed that only $4 \%$ have been referred for further assessment. In majority (38.09\%) the PHM too hasn't detected a hearing impairment and has marked incorrectly, stating that the child's hearing is normal. $28.5 \%$ were not seen by a PHM, and in another 9\% the response regarding hearing is not marked by the PHM. In two cases, PHM has given false reassurance stating that it's a speech delay, and to observe the child till 1 year of age for any improvement in hearing, or addressed it as a developmental delay.

\section{Discussion}

Sensorineural Hearing Loss (SNHL), which affects 2-4 infants per 1000 children, is one of the major causes of childhood disabilities worldwide ${ }^{3}$.

As stated by Huang ${ }^{6}$, early diagnosis of prelingual hearing loss is critical to optimize treatment resulting in a good speech and language development, social and emotional well-being and good academic development. This is important because there is a critical period for optimal language development due to neuroplasticity. Even though FDA criteria for cochlear implantation in children is mentioned as at 12 months of age or older in 2018, recent research indicates implanting below 12 months of age is safe and has positive outcomes ${ }^{(5)}$.

A study done by Knobel on "Are parents aware of their children's hearing complaints? " in Brazil, $2012^{7}$ showed that most parents were not aware of their child's complaints. Which explains the late presentation of children with SNHL as a speech delay to ENT units at about $1-1$ 1/2 years of age.

CHDR, which is developed and issued by the Family Health Bureau of the Ministry of Sri Lanka, is considered as the main document in the National Growth Monitoring and Promotion programme for children under 5 years. Monitoring the hearing response and relevant entries which is located on page 11 of CHDR (published after 2004) is considered as an important tool for early detection of hearing loss in children. With this study we tried to analyze its importance as a tool, the parent's awareness of hearing loss, and the detection of hearing loss by the public health midwife.

We observed that the age of the child at the first diagnosis of the hearing loss spans from less than onemonth up to 2 years and 8 months of age. Most of the children were diagnosed between 18 - 24 months. This is even more than the average age of detection of hearing loss in developed countries, which is 14 
months of age ${ }^{8}$, before universal newborn screening for hearing was implemented. Majority presents as delayed speech rather than hearing loss, which also highlights the parents lack of awareness of the hearing loss.

The age of cochlear implantation spans from 9months to 5 years of age. The majority had their implantation between 3-4 years. The average waiting period for surgery is 2 years. If the hearing loss is detected at newborn period, these children have an opportunity of getting a cochlear implant before the age of $21 / 2$ years.

In our study we found out that only less than a quarter of the parents have marked the responses correctly. Which is $20.7 \%$ at newborn, $22.6 \%$ at 1 month, $22.7 \%$ at 7 months, 9 months and 12 months. Which is similar to the results observed by Watkin" following a retrospective study on "Parental suspicion and identification of hearing impairment", where only a quarter of the children with permanent hearing loss were identified as a result of parental concern.

This shows lack of parental awareness about hearing loss in children and the inability to detect it by using the CHDR as a tool in detecting childhood deafness.

When analyzing the reasons for not marking or incorrect entries, the majority stated that they are not aware about a child's hearing impairment, or they were reluctant to believe or accept it. This shows that parental assessment of the child's hearing is not a reliable indicator. We further observed that some parents did not consider it a necessity to mark the CHDR, which makes it sensitive as a tool in detection of hearing loss.

The PHM is the main primary health care worker in Sri Lanka, whose range of duties include promoting maternal and child wellbeing and to promote health in the community. There are sections on page 12 and 13 in the CHDR which should be filled during their home visits regarding the hearing of the child.

In page 12 and 13 of CHDR the PHM must mark the child's development for each milestone. If they feel the child is having any issue, they should refer for further assessment. We observed that in $38.09 \%$, the PHM hasn't detected a hearing impairment and has marked incorrectly, stating that the child's hearing is normal. In some instances, PHM has given false reassurance stating that it's a speech delay, and to observe the child till 1 year of age for any improvement in hearing or addressed it as a developmental delay. Even though no study has been carried out to assess the knowledge of PHM regarding detection of hearing loss in children in Sri Lanka, a survey carried out by Fernando et.al. ${ }^{10}$ on "Essential public health functions of field health staff in Sri Lanka", shows that their competencies were low in understanding and implementing health promotion programmes. This highlights the need for continuous training programmes and provision of reading materials regarding identification of developmental issues in children, including hearing impairment.

In Sri Lanka, as $99 \%$ of live births take place in hospitals, newborn hearing screening was implemented in December 2019. Since parental awareness and the knowledge of PHM on early detection of hearing loss was poor, and CHDR cannot be used as an important tool in assessing the hearing of children from newborn to 12 months of age this justifies the importance of newborn screening to detect early hearing 
difficulties . Early identification of hearing loss leads to appropriate and timely intervention resulting in good speech and language development and social and emotional wellbeing.

\section{Key messages}

Parental and the PHM's assessment of a child's hearing is not a reliable indicator to detect early sensorineural deafness and CHDR cannot be used as an important tool in assessing it.

We recommend universal newborn screening since $99 \%$ of live births take place in hospitals in Sri Lanka

\section{References}

1. Kumar S. WHO tackles hearing disabilities in developing world. Lancet. $2001 \mathrm{Jul}$ 21;358(9277):219.https://doi.org/10.1016/S0140-6736(01)05460-5

2. Watkin PM, Baldwin M. Identifying deafness in early childhood: requirements after the newborn hearing screen. Arch Dis Child. 2011 Jan;96(1):626.https://doi.org/10.1136/adc.2010.185819. PMid:21047829

3. Huang BY, Zdanski C, Castillo M. Pediatric sensorineural hearing loss, part 1: Practical aspects for neuroradiologists. AJNR Am J Neuroradiol. 2012 Feb;33(2):2117.https://doi.org/10.3174/ajnr.A2498. PMid:21566008 PMCid:PMC7964818

4. Davis A, Wood S. The epidemiology of childhood hearing impairment: Factors relevant to planning of services [Internet]. Vol. 26, British Journal of Audiology. 1992. p. 7790.https://doi.org/10.3109/03005369209077875.PMid:1628120

5. Graham JM, Scadding G, Bull PD. Pediatric ENT. Springer Berlin Heidelberg; 2007. 508 p. https://doi.org/10.1007/978-3-540-33039-4

6. Huang BY, Zdanski C, Castillo M. Pediatric sensorineural hearing loss, part 1: Practical aspects for neuroradiologists. AJNR Am J Neuroradiol [Internet]. 2012;33(2):211-7. https://doi.org/10.3174/ajnr.A2498.PMid:21566008 PMCid:PMC7964818

7. Knobel KAB, Maria Cecília Marconi. Are parents aware of their children's hearing complaints? [Internet]. Vol. 78, Brazilian Journal of Otorhinolaryngology. 2012. p. 27-37. https://doi.org/10.5935/1808-8694.20120005.PMid:23108817

8. Task Force on Newborn, Hearing I. Newborn and Infant Hearing Loss: Detection and Intervention. $\quad$ Pediatrics. $\quad 1999 \quad$ Feb $\quad$ 1;103(2):52730.https://doi.org/10.1542/peds.103.2.527.PMid:9925859

9. Watkin PM, Baldwin M, Laoide S. Parental suspicion and identification of hearing impairment. Arch Dis Child. 1990 Aug;65(8):846-50.https://doi.org/10.1136/adc.65.8.846. PMid:2400221 PMCid:PMC1792472

10. Fernando,D., Gunawardena,N., \& Weerasinghe,C., 2006. Survey on Essential Public Health Functions in Sri Lanka, Faculty of Medicine, University of Colombo. https://doi.org/10.4038/jecpsl.v11i2.8255 